\title{
Plights and Outlets of Improving Teachers Curriculum Leadership in Rural Areas in Western China
}

\author{
Yan-Mei SONG
}

\author{
School of Foreign Language, Nanyang Institute of Technology, Nanyang, Henan, China, 451191 \\ Email: songyanmei73@126.com
}

Keywords: Rural Area in Western China; Teachers' Curriculum Leadership; Predicaments; Outlets

\begin{abstract}
Teachers' curriculum leadership research has been becoming a hot area. Investigation shows that there are many plights in rural area in western China, including poor awareness, lacking effective professional training, lower ability and level in leadership, lagged curriculum leadership system and so on. To improve these predicaments, efforts should be made on strengthening training, building up the ranks of teachers, realizing the integration of teachers' professional development and curriculum leading ability and innovating leadership system of curriculum management.
\end{abstract}

\section{Introduction}

As important participators, teachers' curriculum leading ability and professional development play a crucial effect in schools' curriculum implementation and development. Teachers' participation is not only the effective use of modern leading theory results in school curriculum leadership, but also a necessity of deepening the reform and development of education. The thesis is to introduce the research situation, the plights and some effective ways to solve the problem.

\section{The Brief Introduction of Teachers' Curriculum Leadership}

\section{The Connotation of Teachers' Curriculum Leadership}

Teachers' curriculum leadership mainly refers to teachers' ability in providing relative suggestions on school's curriculum design, development and implementation, including curriculum designing, developing and implementing ability. You can understand the conception from the following two points.

Firstly, teachers' curriculum leadership means that teachers are the leaders in developing curriculum. On the one hand, they structure school calendar of all-year-round teaching activities, draw up the plan of each unit, enrich a curriculum, remedy teaching and evaluate curriculum regularly in separate, group or the whole students' ways from several directions in the class. On the other hand, teachers' curriculum leadership is not just instructing and guiding teachers. Most importantly, it should lead teachers to share their teaching experience, strengthen teachers interaction, listen to life experience each other, trying to find some connections with others. ${ }^{[1]}$ In addition, teachers should possess the following traits to respond in curriculum leadership: curriculum and teaching professional knowledge, thorough understanding students' development and study, being good at communication, being responsible, good accountability of problem solving and conflict dealing and being trusted.

Secondly, teachers' curriculum leadership is a kind of practical wisdom in essence. This kinds of practical wisdom includes the following forms. The foundation of teacher curriculum leadership --a special sensation of teaching mission. The spring of teachers curriculum leadership ----exhibiting curriculum attraction from teachers hearts. The boast of teacher curriculum leadership --- the life network of teacher team. The best way to teacher curriculum leadership ---- teachers being the masters to explore true power of minds.

\section{The Roles of Teachers Curriculum Leadership}

Firstly, producer of curriculum awareness ----- teachers are needed to qualify three kinds of curriculum awareness. One is curriculum professional awareness, that is, teachers must qualify 
themselves for relative content knowledge, general teaching knowledge, curriculum knowledge, knowledge of teaching of school subjects, knowledge of students and their qualities, understanding education environment 、 aims of education and its value. One is curriculum critical consciousness; that is to say, teachers should have the awareness to criticize preset curriculum, to retrospect life and teaching practice, to recreate the teaching world and to reconstruct personal professional experience. Another is curriculum resource awareness, that is, it is necessary for teachers to have the awareness to use textbooks creatively, to develop and utilize all kinds of curriculum resource.

Secondly, vanguard of curriculum enforcement and development----in the course of the new curriculum reform, teachers are the mainstay. Not only have they the ability to enforce and develop curriculum, but also they are expected to be leaders.

According to the current requirements of the curriculum reform, teachers are required to teach creatively, from devoted executors to curriculum procreators.

Thirdly, facilitators of students autonomous learning and teachers professional development---for one reason, the highest appeal for curriculum leadership conception is to improve students learning efficacy and teachers' professional development. For the other reason, teachers face students' study and teachers' professional development more regularly and directly. Therefore, both affairs must be dealt with efficiently in the course of curriculum leading.

Fourthly, teachers helpers ---- this is the most important role to teachers who undertake curriculum leading task. To those teachers who have the same interest and educational belief, they care for each other, participate actively in curriculum reform and development, no matter what subjects they teach, what fields they study or how old they are.

Lastly, people who construct the learning community----the work of curriculum leadership is launched based on share and invitation, so it is a necessity for the leaders to construct learning, cooperation and mutual trust atmosphere and to construct the learning community. The learning community focuses on members' commitment, responsibility and duty and depends on the same norm, values, professional spirit, community spirit and natural dependence among members.

\section{The Authority of Teachers' Curriculum Leadership}

Firstly, teaching autonomy right-----it is the objective of teacher professional development and is also a necessity for teachers work. Teachers' teaching autonomy rights include developing curriculum, drawing up curriculum plan, choosing textbooks and curriculum evaluation method. Three phases on teaching autonomy are emphasized specially. The first is to develop curriculum, the second is to construct active classroom atmosphere and the last is to establish democratic and equal class life.

Secondly, curriculum leadership right----as one of curriculum leaders, teachers are expected to participate in curriculum decision, to listen carefully to other benefit units ideas, to draw up school-based curriculum plan through discussing together. This right is embodied in three aspects: one is participating curriculum decision, one is choosing textbooks freely, and another is constructing latent curriculum system.

Thirdly, professional development right-----teacher professional development is a condition of curriculum development and it is a basic guarantee of educational quality. At the same time, teacher professional development is also a substantive right of teacher self-development, necessary content of teacher career planning and a decisive factor for teachers realizing the change from job through profession to career in teacher's personal working experience.

\section{Plights Facing Teachers' Curriculum Leadership in Rural Areas in Western China}

Based on the relative theory, status quo about teachers' curriculum leadership in rural areas in western China was investigated with questionnaire and interview. The result shows that teachers' curriculum leadership in rural areas in western China has been strengthened to a certain extent since the 2001 curriculum reform. But there are still the following problems: 


\section{Teachers' Curriculum Leading Consciousness is Weak}

It is shown in the investigation that most teachers only have teaching consciousness instead of curriculum consciousness. That is to say, teachers only care about the subjects that they teach, but they never care about the school curriculum development. What they are doing is just to finish the task from the school. Many teachers think that curriculum development is decided by school leaders, having nothing with teachers and their task is to teach students. This thought leads to weak curriculum leadership among teachers. Most teachers are used to utilizing textbooks and teaching material, lacking the consciousness of curriculum participation and development. They are used to following the instructions, lacking the curriculum leadership consciousness. In their eyes, the less responsibility, the better. Deep in their hearts, the less pressure, the better. In addition, many schools are managed according to seniority and institutional system. Administrative means from top to bottom keeps the school running, depriving most teachers of their rights and chances to be school leaders.

\section{Teachers Lack Effective Professional Training}

The investigation shows that in teachers' view the difficulty in school curriculum leadership lies in three aspects: teachers lacking professional skills in developing curriculum (20.8\%), school lacking funds and equipment (18.1\%), teachers lacking time which results from heavy teaching tasks (31\%). In addition, some teachers (30.2) think that the effect of curriculum reform is relative to the propelling of local educational administrative department. Some teachers (36\%) view that teachers' curriculum implementation is connected with the effect of curriculum reform. From the above, we can draw two conclusions. The first, to solve this difficulty, one major way is to increase investment to basic education from the external environment. The second, from the point of view of teachers themselves, the best way to improve teachers' professional skill is effective professional training, especially good quality and high level training.

\section{Teachers' Participation Level in Curriculum Leadership is Lower}

On what level teachers participate in curriculum planning and designing affects not only the result of curriculum designing but also the course of curriculum implementation. However, teachers' participation level in curriculum leadership is low at present, which can be illustrated from three aspects. The first, teachers don't participate or only participate on lower level in school curriculum's decision, design, development and implementation. They usually accept school's arrangement passively, especially in using curriculum resource, even textbooks. For example, Science in many primary schools turns out to be a mere formality because teachers aren't aware of the city tendency in content arrangement and other unfavorable factors in natural environment, economic and social condition and education developing level. The second, teachers don't have time or energy because of heavy teaching tasks. One reason is that teachers still pay so much attention to students' marks that they spend a lot of time to improve students' school achievements. The other reason is that work pressure coming from teaching task is too heavy to spare time in participating curriculum leadership. The third, teachers are out of leading ability and the leading level is low. As teachers are one of the main bodies of curriculum leadership, it is important to form teachers' teaching leadership to improve curriculum leadership. Class leadership embodies teachers' teaching leadership. Class leadership means that teachers have influence on classroom atmosphere through effective performance in the classroom under the concept of "teachers guiding, students subjects" and create active and constructive course to improve teaching effect gradually in which teacher and students learn together by using democratic, sharing, cooperative, constructive, critical and self-reflective strategies. Active classroom leadership appears students and teachers taking care of each other, teachers respecting students' independence, making the best use of situation, active thinking, harmonious teachers-students relationship and good results.

\section{Curriculum Leadership System Lags Behind and Its Mechanism Lacks Vigor}

In this Curriculum Reform in Elementary Education, it is required that curriculum management 
includes three levels: National Curriculum, place curriculum and school curriculum. In fact, National Curriculum and place curriculum are dominating while school curriculum needs to be improved further. Teachers curriculum leadership hasn't been put on the agenda. In other words, curriculum leadership system construction lags behind in western China. Three-level curriculum leadership system hasn't been set up and present management is extensive. From the micro view, school curriculum operation mechanism lacks vigor, which results in teachers' weak awareness and low participation ability in curriculum leadership.

\section{Outlets to Improve Curriculum Leadership in Rural Areas in Western China}

\section{Strengthen Training to Improve Teachers' Curriculum Leadership Quality}

Since teachers' curriculum leadership lags behind in rural areas in western China, time and efforts should be spared in training teachers to improve their leading quality by educational administrative department. Firstly, curriculum leadership should be included in the training. The contents are: basic theory on curriculum leadership, such as its natal background, concepts, tasks and skills; teachers professional development and curriculum leadership, such as teachers professional development modes, professional development orientation, the relationship between professional development and curriculum leadership; curriculum leadership and school curriculum development, such as relative basic theory and practice; the relationship between curriculum leadership and school curriculum development; teachers curriculum leadership and Curriculum Evaluation.

Secondly, full training needs to be carried out to promote teachers' new curriculum Execute Power and to improve teaching efficiency. Curriculum Execute Power is based on teachers' correct understanding towards curriculum. It is also fairly necessary to improve teachers' teaching technique and strategic capability so that they can change advanced teaching theories and methods into effective teaching action. Thirdly, perennial efforts by teachers themselves are badly needed because teachers' self-quality is the decisive factor for them to participate availably in curriculum leadership. Teachers themselves should improve and develop curriculum quality in curriculum consciousness and ability by way of taking part in training, attending refresher courses, subject exploration, action research and so on. In the course of these activities, most teachers will build up their confidence, make clear curriculum leadership task, strengthen their abilities and improve their curriculum leadership quality step by step.

\section{Reinforce Teachers' Team to Share Wisdom for Teachers' Curriculum Leadership}

It is also very important to build up and reinforce teachers' team. For teachers, team work can boost morale, better job satisfaction and interpersonal relationship and improve teaching quality. Team work is helpful to strengthen school comity and teachers self-efficiency, to mould and defend the school culture and to facilitate the form of informal communication network. Team work can make teachers fling into more and more challenging work and taste self-satisfaction, happy and substantial so that they can make more meaningful and greater success. Teacher team construction can not only raise the whole level of school faculty force, but also improve their authority, specialty, creativity and academic level, changing each other going its own way. To develop school curriculum leadership team, the most important is the principal's participation and attention. As a main leader in school curriculum leadership team, the principal has to learn others' experience in curriculum leading and improve his own professional development and curriculum leading ability. At the same time, the principal has to lead all the members, integrate resource, adjust organizational structure, and execute curriculum and teaching leading. In addition, dean of studies, the capital of teaching research group and the teacher who takes charge of one grade play a dominant role in school curriculum leadership because as middle level administrator in school, they are like a bridge between ideal and practice by driving the faculty, community members and parents participating in some aspects of curriculum. High efficient school curriculum leadership team needs teachers to exert their professional knowledge and ability and collective wisdom so that the efficiency of curriculum leadership can be promoted. 


\section{Accelerate Teachers' Professional Development, Unifying Improving Teachers' Curriculum Leadership and Their Professional Development}

In traditional teaching, teachers are the curriculum executors instead of designers and developers. In their minds, their task is teaching students according to textbooks instead of developing curriculum. To change this situation, curriculum development and teachers' professional development should be furthered together.

The principal ought to be concerned about teachers' participation, encourage teachers to take part in curriculum decision and curriculum reform experiments, reflect actively their teaching practice, seek deep impetus of curriculum reform, lead and stimulate teachers' professional development so that teachers and new curriculum grow up day by day. According to modern education theory, stimulating teachers' self-reflective study can propel teachers' development indeed. This kind of self-reflective study requires that teachers take part in the research in a penetrating way, pay much attention to research course, be concerned about self-development with research, and adhere to reflect the problems in their own teaching. Only in this way can they really benefit their profession development. [4]

\section{Innovate System and Mechanism of Curriculum Management}

The first is to build 4-level curriculum leadership system and mechanism, which are co-managed by the country, the state, the school and the teachers. Nowadays the main tendency of primary and middle curriculum decision mechanism reform in western countries is that it is co-managed by the country, the state, the school and the teachers. [5] This experience should be absorbed by Chinese schools to build 4-level curriculum leadership system and mechanism with Chinese characteristics.

The second is to improve school operation mechanism to provide some leading space for teachers. The principals should delegate the management of curriculum to school teachers. At the same time, a kind of school culture with participating and sharing feature needs to be formed. "It is very necessary to awake the consciousness of curriculum leadership in Curriculum Reform in Elementary Education in China, while what is needed to eliminate examination-oriented education system and to create a kind of better school culture is democratic curriculum leadership." ${ }^{[6]}$ As one principal educational subject, teachers should have the right to participate in curriculum leadership. To achieve this, on the one hand, the role of old teaching research group in curriculum needs to be brought into fullest play; on the other hand, curriculum leadership organizations such as curriculum development research group, curriculum direction and evaluation group and curriculum steering committee can be set up to absorb more gifted teachers to take part in school curriculum development.

The third is to set up new curriculum management system to give teachers more rights. Giving teachers more rights means that principals adjust their roles and leading methods to create active school environment, to encourage teacher self-management and to set up work team. Under the new curriculum management system, the power of curriculum development should be given to teachers. It will provide a platform for teachers to give full scope to creativity as curriculum subject so that their education belief and value pursuit can be embodied through curriculum development. In fact, as dominators of curriculum reform, teachers should be given some rights to take part in curriculum designing to realize their ideal by using their gifts and wisdom in teaching.

\section{Reference}

[1] Mei-Ju Chen. Demonstration and Deepening of Teacher Specialization: Why, How and the limitation about Teachers' Curriculum Leadership [J]. Journal of Education Research (Tai Wan), 2004(10):19-32.

[2] Li Zhaohui, Chen Xu Yuan, SUN Shuai. Transformation and Adaptation: the Countermeasures of Parental Involvement in Curriculum Reform [J]. Journal of Teaching and Management, 2002, (9): $40-42$. 
[3] Li Zhaohui, Liu Shuren. From "In Itself" to "For Itself": the Tactics for Principals to Curriculum Leadership [J]. Educational Science Research, 2006(12):39—42.

[4] Shen Xiaobei, Luo Ruhu. A study of Curriculum Leadership [J]. Educational Research, 2004, (10): 54-58.

[5] Ding Nian-jin. Changes of Curriculum Decision-making Mechanism in Western Elementary and Secondary Schools [J]. Elementary and Secondary Schooling Abroad, 2005, (6):6-11.

[6] ZHONG Qi-quan. From "Administrative Authority" to "Professional Authority" --- Perplexities and Issues on "Curriculum Leadership" [J]. Exploring Education Development, 2006, (4A):1-7 